\title{
Article
}

\section{In-flight Lift and Drag Estimation of an Unmanned Propeller-Driven Aircraft}

\author{
Dominique Paul Bergmann ${ }^{1, *}$, Jan Denzel ${ }^{1}$, Ole Pfeifle ${ }^{2}$, Stefan Notter ${ }^{2}$, Walter Fichter ${ }^{2}$ \\ and Andreas Strohmayer ${ }^{1}$ \\ 1 Institute of Aircraft Design (IFB), University of Stuttgart, Pfaffenwaldring 31, 70569 Stuttgart, Germany; \\ jan.denzel@ifb.uni-stuttgart.de (J.D.); andreas.strohmayer@ifb.uni-stuttgart.de (A.S.) \\ 2 Institute of Flight Mechanics and Controls (iFR), University of Stuttgart, Pfaffenwaldring 27, \\ 70569 Stuttgart, Germany; ole.pfeifle@ifr.uni-stuttgart.de (O.P.); stefan.notter@ifr.uni-stuttgart.de (S.N.); \\ walter.fichter@ifr.uni-stuttgart.de (W.F.) \\ * Correspondence: dominique.bergmann@ifb.uni-stuttgart.de; Tel.: +49-711-685-60342
}

Citation: Bergmann, D.P.; Denzel, J.; Pfeifle, O.; Notter, S.; Fichter, W.; Strohmayer, A. In-flight Lift and Drag Estimation of an Unmanned Propeller-Driven Aircraft. Aerospace 2021, 8, 43. https://doi.org/10.3390/ aerospace 8020043

Academic Editor: Roberto Sabatini Received: 14 December 2020 Accepted: 1 February 2021 Published: 6 February 2021

Publisher's Note: MDPI stays neutral with regard to jurisdictional claims in published maps and institutional affiliations.

\section{Copyright: (c) 2021 by the authors.} Licensee MDPI, Basel, Switzerland. This article is an open access article distributed under the terms and conditions of the Creative Commons Attribution (CC BY) license (https:// creativecommons.org/licenses/by/ $4.0 /)$.

\begin{abstract}
The high-power density and good scaling properties of electric motors enable new propulsion arrangements and aircraft configurations. This results in distributed propulsion systems allowing to make use of aerodynamic interaction effects between individual propellers and the wing of the aircraft, improving flight performance and thus reducing in-flight emissions. In order to systematically analyze these effects, an unmanned research platform was designed and built at the University of Stuttgart. As the aircraft is being used as a testbed for various flight performance studies in the field of distributed electric propulsion, a methodology for precise identification of its performance characteristics is required. One of the main challenges is the determination of the total drag of the aircraft to be able to identify an exact drag and lift polar in flight. For this purpose, an on-board measurement system was developed which allows for precise determination of the thrust of the aircraft which equals the total aerodynamic drag in steady, horizontal flight. The system has been tested and validated in flight using the unmanned free-flight test platform. The article provides an overview of the measuring system installed, discusses its functionality and shows results of the flight tests carried out.
\end{abstract}

Keywords: unmanned aircraft; thrust determination; flight testing; e-Genius-Mod; free-flight wind tunnel

\section{Introduction}

While investigating the flight performance of new aircraft configurations or technologies, knowledge about aerodynamic and flight mechanical parameters is required to understand their impact on the aircraft. From the perspective of aircraft design, one main focus is the impact on flight performance when investigating for example the effects of new propulsion technologies or aircraft configurations. To investigate and assess the flight performance, the determination of lift and drag is of major importance. Especially the determination of drag from flight tests with an unmanned propeller aircraft is a challenging task.

Flight tests with unmanned aircraft systems (UAS) have become increasingly important in recent years. Scaled platforms are not only used as payload carriers, but also for the analysis of novel aircraft configurations or for the assessment of unconventional propulsion systems.

The lower costs as well as the reduction of risks especially in the area of unconventional configurations militate in favor of using unmanned systems. Typical examples for demonstrators used to study flight dynamic effects are the AlbatrossONE [1] of Airbus and the platform of the project FLEXOP (flutter free flight envelope expansion for economical performance improvement) [2]. In the case of the AlbatrossONE, gust loads are minimized 
by structural interventions in the area of the wing tip, while aeroelastic effects on the wing are observed with the help of the carrier platform FLEXOP. To investigate the impact on flight performance of new technology on an aircraft configuration, a direct comparison between base line configuration and modified aircraft is of interest, as demonstrated by NASA with its Area-I Prototype Technology Evaluation and Research Aircraft (PTERA) [3]. In the research, the PTERA platform was modified to investigate for example combined circulation control [4] and a spanwise adaptive wing [5].

Unmanned aircraft are an important tool to investigate new aircraft configurations and novel aviation technologies at University of Stuttgart, [6]. New technologies or concepts can be flight-tested with little effort, low costs and manageable project risks after initial theoretical investigation. This way, research concepts can reach a much higher feasibility, of particular interest to industry, to close the gap between upstream research and industrial exploitation. This can build a bridge, demonstrating technologies at a higher technology readiness level (TRL). Innovative ideas can be demonstrated and validated in a relevant environment which corresponds to a TRL 5/6. However, there are limitations due to the degree of scaling of the technologies under consideration.

A disadvantage for the investigation of flight performance with scaled unmanned aircraft is the limited data available for the different aircraft system components. When investigating the flight performance, propeller characteristics and efficiency of the individual components of the propulsion system are of specific interest.

The Institute of Aircraft Design (IFB) at the University of Stuttgart has developed the "e-Genius-Mod" test platform based on this background. The platform is modelled on a scale of 33.3\% of the electrically powered "e-Genius" aircraft [7], which is also designed, manufactured and operated by the institute. In this particular case, the UAS was realized as Froude-scaled version [6].

Due to the modular design of the testbed, different configurations can be easily realized, which allows an adaptation to different applications. Furthermore, the geometry of the fuselage offers ideal conditions for accommodating various payloads.

For the purpose of identifying the aircraft and measuring flight performance, it is essential to map the aerodynamic parameters of the system. The most important parameters are the aircraft drag and the lift polar. From the correlation of the coefficients for lift and drag of the aircraft, a direct statement about the performance and energy consumption can be derived. The gliding characteristics, the required power installed and the potential range are important parameters that are required to compare different propulsion concepts and identify their impact for a prospective aircraft design.

In order to obtain reliable drag and lift polar, manned test aircraft often would carry out comparative flights with calibrated systems. Especially in the field of gliding, where a precisely identified system is very important, such survey flights are still state of the art today.

In the unmanned area, such survey flights are difficult to carry out. For UAS, a method for a glider model is described by Edwards [8]. Due to the induced drag of the propeller system, this method is not useful for the proposed identification of propeller-driven UAS. A method to identify drag of a propeller aircraft was developed by Norris and Bauer [9]. Alternatively, if available, a model for the propeller wind-milling drag or thrust could be used to apply this method. For the e-Genius-Mod testbed, a different approach was taken. In order to record the performance data, a measurement system was developed that is capable of recording the thrust values required during the flight. Such systems have not yet been installed in large UAS, but have only been used sporadically on manned aircraft. For the aerodynamic characterization of smaller UAS, on-board thrust measurements have been performed in the past, such as presented by M. Bronz and G. Hattenberger [10]. However, for the identification of the flight performance and to show the feasibility of novel technologies in aviation the measurement of drag is essential.

Although the thrust values for the operation of a propeller-driven system can be measured without any problems when stationary, the thrust values during flight are not 
comparable due to the induced flow to the propeller without prior identification of the propeller via wind tunnel experiments. The efficiency of the drive also changes significantly under different flow conditions. Therefore, a direct, mechanical thrust measurement in flight is of significant advantage.

\subsection{Challenge of Current Research Using Unmanned Aircraft as Free-Flight Test Platform}

A current research topic at the University of Stuttgart is how to use unmanned propeller-driven aircraft as a test platform to determine their flight performance without knowing specific data of propeller and powertrain. This ability is for example required to compare different propulsion configurations like Wing Tip Propellers (WTP) to a basic configuration in flight. Based on the collected flight data, the estimated benefits of this technology in flight should be validated and demonstrated. For this purpose, the basic in-flight measurement system of the test platform is extended with a system to measure the thrust of the propeller in-flight.

For this, the assumption was made that in steady horizontal flight the thrust performed by the propeller corresponds to the aerodynamic drag acting on the aircraft.

\subsection{The Modular Test Platform e-Genius-Mod}

The free-flight platform e-Genius-Mod (Figure 1) is established as a technology test bed to demonstrate new technologies for future aircraft design in a relevant environment. The UAS test platform [6] is used for academic and innovative research projects to investigate scaling similarities of free flight models and to demonstrate new technologies up to TRL 6 . The modular design of the test bed is ideally suited for the investigation of new aircraft configuration solutions for distributed electric propulsion systems. The size of the aircraft with a wingspan of $5.62 \mathrm{~m}$, maximum take-off weight of $40 \mathrm{~kg}$ and a payload capacity of more than $10 \mathrm{~kg}$ [6] is suited to perform prospective investigations. The maximum possible flight time is up to $100 \mathrm{~min}$, depending on the particular battery capacity and the payload weight. An overview of the technical data of the e-Genius-Mod is summarized in Table 1.

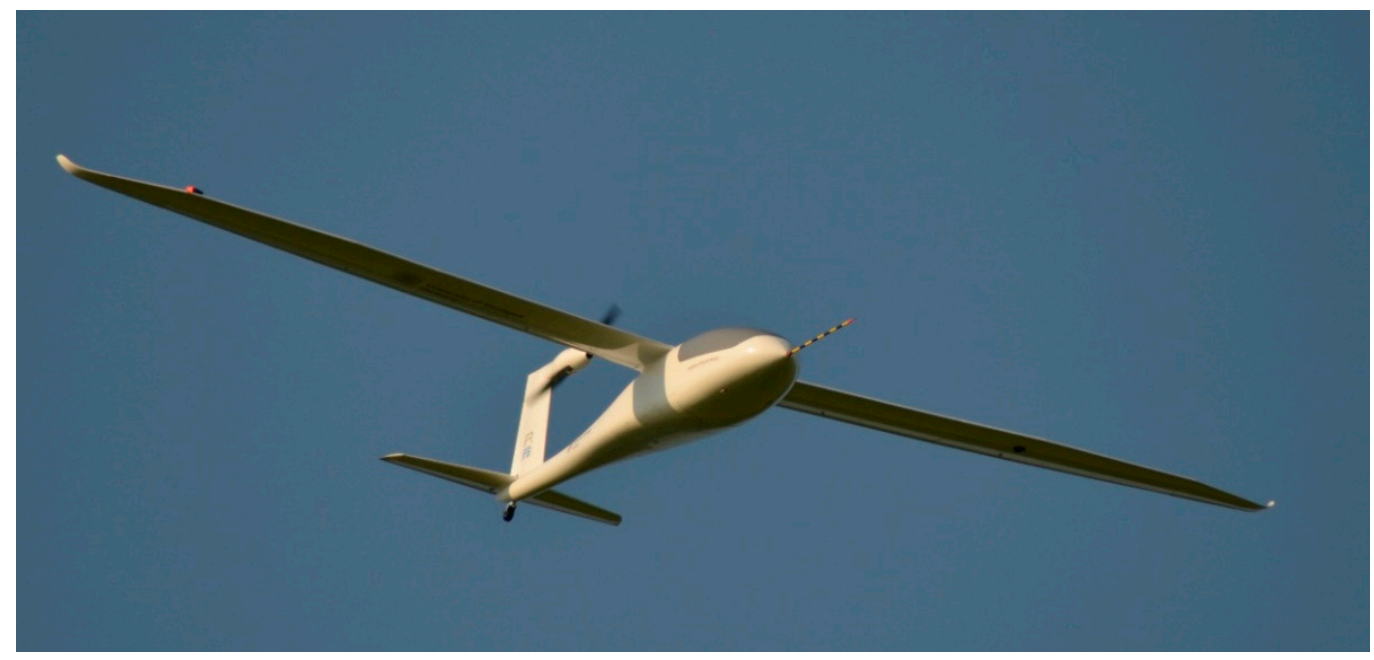

Figure 1. Free-flight test platform e-Genius-Mod. 
Table 1. Technical data of the e-Genius-Mod [6].

\begin{tabular}{cc}
\hline Aircraft Parameter & Value \\
\hline Wing span & $5.62 \mathrm{~m}$ \\
Wing area & $1.56 \mathrm{~m}^{2}$ \\
Aspect ratio & 20.2 \\
Length & $2.95 \mathrm{~m}$ \\
Take of mass * & $34.9 \mathrm{~kg}$ \\
Electric drive power & $5 \mathrm{~kW}$ (Plettenberg Terminator 30/8 Evo) \\
Max. thrust & $156 \mathrm{~N}$ \\
Propeller & RASA $24 \times 12$ \\
Design speed & $24.8 \mathrm{~m} / \mathrm{s}$ \\
Battery capacity & $42 \mathrm{Ah}(44.4 \mathrm{~V})$ \\
\hline
\end{tabular}

*flight test characteristic.

The test bed e-Genius-Mod is an extension of the full-scale aircraft for further investigation of electric flight and new aviation technologies. For this reason, the test platform is equipped as a free flight wind tunnel. In order to perform measurements in steady, horizontal flight, an autopilot is used to steer the aircraft along a predefined path of constant altitude and velocity, as described in [11]. The measurement system ensures the synchronous logging of all relevant variables (Table 2), as further detailed in Section 3.

Table 2. Basic measurement equipment of the free-flight wind-tunnel.

\begin{tabular}{|c|c|c|}
\hline Variable & Sensor Type & Unit \\
\hline $\begin{array}{l}\text { linear accelerations } \\
\text { rotation rates }\end{array}$ & $\begin{array}{l}\text { IMU } \\
\text { IMU }\end{array}$ & $\begin{array}{l}\text { Board computer } \\
\text { (Pixhawk4) }\end{array}$ \\
\hline $\begin{array}{l}\text { position } \\
\text { attitude } \\
\text { velocity }\end{array}$ & $\begin{array}{c}\text { (IMU, GPS, magnetometer, } \\
\text { barometer) estimation via } \\
\text { Kalman filter }\end{array}$ & \\
\hline $\begin{array}{l}\text { true air speed } \\
\text { angle of attack } \\
\text { angle of sideslip } \\
\text { air density }\end{array}$ & $\begin{array}{l}5 \text { hole-probe } \\
\text { temperature sensor }\end{array}$ & $\begin{array}{c}\text { AirDataBoom } \\
\text { (Vectoflow /VectoDAQ } \\
\text { Air Data Computer) }\end{array}$ \\
\hline $\begin{array}{c}\text { deflection angle of the control } \\
\text { surfaces }\end{array}$ & $\begin{array}{l}\text { magnet sensor } \\
\text { rotor sensor }\end{array}$ & $\begin{array}{l}\text { Actuator (Volz } \\
\text { DA15N) }\end{array}$ \\
\hline
\end{tabular}

The basic free flight measurement equipment can be easily expanded by connecting additional sensors to the dedicated bus system used solely for measurement data.

Electric propulsion systems allow for new design alternatives in terms of propulsion integration and aircraft design. To investigate and demonstrate new concepts, a modular testbed like the unmanned scale model is a very useful and flexible tool. The demonstration of innovative concepts like distributed propulsion on a manned aircraft would be expensive and time intensive and not useful for research with open-ended findings at this early stage. With its modular airframe design, the e-Genius-Mod is the basis for an efficient and systematic research of the various effects of distributed propulsion.

Onboard thrust measurements on a UAS pose a particular challenge. On the one hand, it must be possible to carry out reliable, calibrated measurements, and on the other hand, the sensor systems are subject to narrow limits in terms of dimensions and weight. For this purpose, sensor systems specifically designed for the e-Genius Mod were developed, calibrated and tested in wind tunnel experiments before installation.

The thrust values are in many respects informative for the evaluation of the flight controller itself, as well as for the assessment of the efficiency of an engine. In general, they establish a direct relationship to aerodynamic quality and, in case the electrical power consumption is known, allow a direct statement about the overall efficiency of the 
corresponding powertrain. Especially when considering several distributed engines, it is possible to make a reliable statement about the overall energy balance onboard the platform.

The aim of the thrust measurements is to prove the expected positive effects of the distributed engines in terms of quality, and, in further steps, to make statements about where on the aircraft they can be used most efficiently. Furthermore, previously performed simulations are to be validated with these measured values.

\section{Research Objective}

To assess and validate the impact of a novel configuration or technology in flight, knowledge of the flight performance is of vital importance. Required basic information in aircraft design are the aerodynamic coefficients for lift $\left(C_{L}\right)$ and drag $\left(C_{D}\right)$ of an aircraft with respect to the angle of attack $(A o A)$. Therefore, the objective of this research is the identification of the $C_{L}-C_{D}, C_{L}-A o A$ and $C_{D}-A o A$ polars in-flight. For the investigation of these coefficients in-flight the following well-known approach is proposed as a starting point.

While the investigations are carried out under cruise conditions, it is assumed as a basis for the investigations that the measurements are carried out in a non-accelerated (steady) horizontal flight. This allows to establish the balance of forces in flight direction and perpendicular to it respectively:

$$
\begin{aligned}
& \operatorname{DRAG}(\mathrm{D})=\operatorname{THRUST}(\mathrm{T}) \\
& \operatorname{LIFT}(\mathrm{L})=\operatorname{WEIGHT}(\mathrm{W})
\end{aligned}
$$

Thrust will be directly measured between engine and engine mount. The measured force corresponds to the force acting on the aircraft caused by the propeller thrust. With

$$
T \approx D=\frac{\rho}{2} * v^{2} * C_{D} * S
$$

and the knowledge about the true air speed $(v)$ and air density $(\rho)$, we can directly determine the drag coefficient $\left(C_{D}\right)$ of the aircraft by assuming drag $(D)$ and thrust $(T)$ as balanced. $S$ describes the reference wing area of the test platform. True air speed and air density will be measured with the air data boom installed in the nose of the aircraft (Table 2). A small deviation has to be considered by the frictional forces of linear bearings in the thrust measurement unit which can be eliminated by a calibration.

The lift coefficient $\left(C_{L}\right)$ can be determined by the following equation:

$$
W=L=\frac{\rho}{2} * v^{2} * C_{L} * S
$$

Since the aircraft is electrically powered by a battery system, the weight is constant throughout the flight. To identify the corresponding angle of attack, the air data boom is used. Angle of attack and angle of sideslip are measured with a five-hole probe. As the measured values of the different sensors are synchronised, the coefficients of lift and drag can be described directly in relation to the $A \circ A$. The measured $A \circ A$ has only to be corrected by its installation position in relation to the wing. In this way, the direct connection between $A o A$ and the corresponding lift and drag values should be representative in flight. Larger values of lift and drag are to be expected with an increasing of the $A o A$.

\section{Approach for the Flight Test Scenario}

The approach for the flight test scenario is based on the assumptions made in Section 2 to investigate the flight performance under the condition of a steady horizontal flight and with a zero-wind condition for the atmosphere.

However, considering the reality of free-flight tests, perfect atmospheric conditions will never be achieved. To meet these requirements to some degree, the flight tests are carried out in the early morning on days with calm atmosphere. The impact of atmospheric 
disturbances was estimated in [12]. To realize a statistical accuracy of the data measured in flight, the data for a single measurement point is collected over a minimum of four legs with two different flight directions.

To determine the thrust during flight, a measuring system is installed between the electric engine and the engine mount to measure the tensile forces. The occurring tensile forces correspond to the thrust generated by the propulsion system.

The thrust measurement is particularly relevant due to its direct correlation with the aerodynamic drag. The investigations are carried out under cruise conditions, i.e., steady, horizontal flight. For the investigation, a flight track is chosen which allows the longest possible horizontal legs. The limiting factor for the tests is the current regulatory framework, which specifies a maximum flight envelope for the tests in the permitted airspace.

The measurement flights are performed with an autopilot in control to achieve steady, horizontal flight and high repeatability. For the test flight a circuit with maximized straight segments (legs) in-between is chosen. Given the airspace restrictions, the leg on which the measurements can be made is nearly $1000 \mathrm{~m}$ long. Figure 2 represents the flight path of a measurement flight at $300 \mathrm{~m}$ altitude.

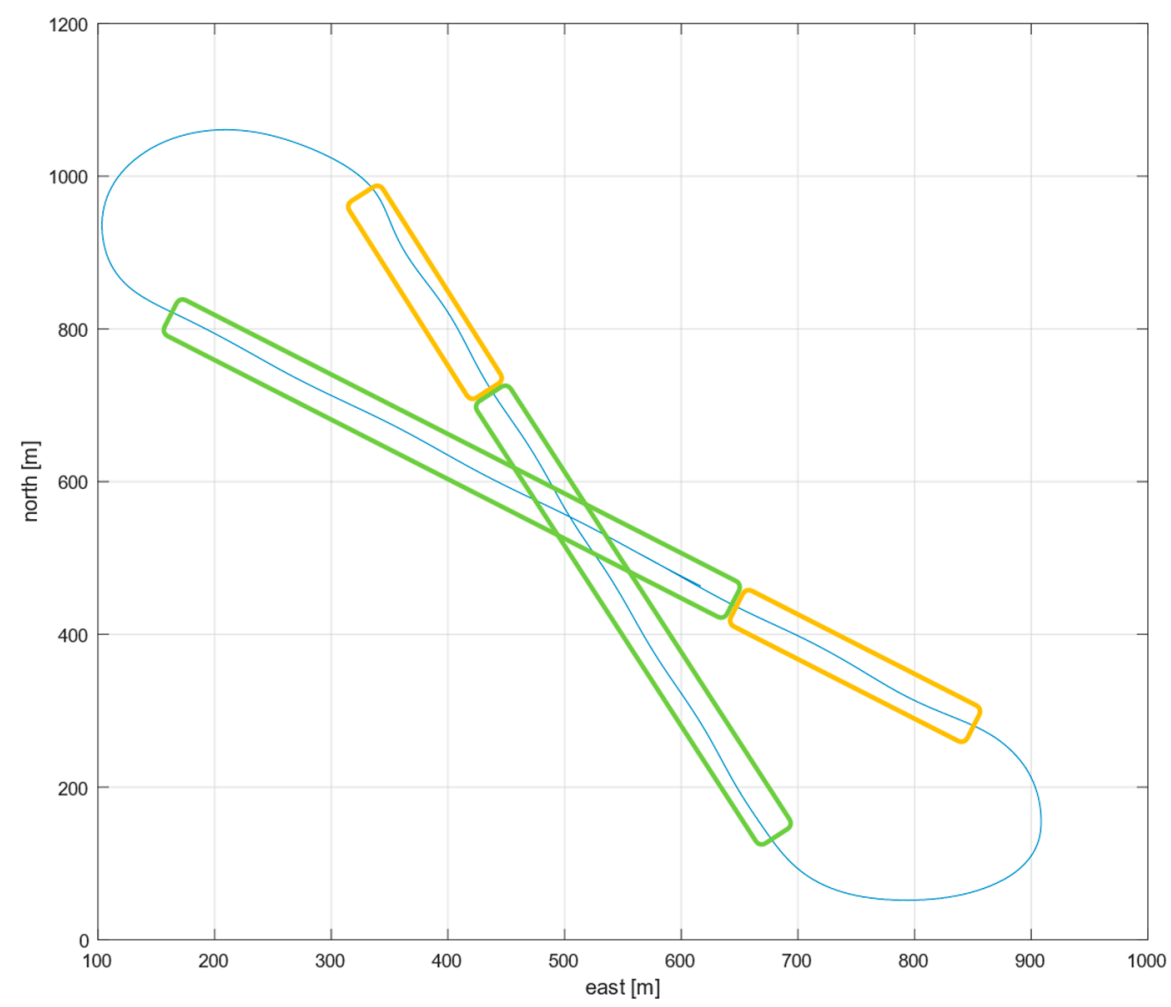

Figure 2. Flight track—sections of measurement (green); level off sections (orange).

The legs are divided into two segments. The first segment is the "level off section". After the turn, airspeed, altitude and attitude are stabilized in this section. Data in this section will not be considered. In the section of measurement, a stabilized flight attitude is expected and the data will be used for the analysis of lift and drag. As there will be no perfect steady horizontal flight with constant altitude and airspeed, limits for the deviation in roll angle, airspeed and altitude are set, to assign a confidence rating to the single leg that is considered in the evaluation. To optimize the steady horizontal flight, the autopilot controls a constant velocity and altitude.

\section{Measurement Unit}

The thrust measurement unit consists of two parts. The sensor unit which contains the sensor itself for direct measurement of the thrust and a self-developed data acquisition 
unit that contains the amplifier module and the interfaces to connect further sensors. The data acquisition unit is also the interface to the data storage.

Recorded values at the propulsion system during flight:

- Thrust

- $\quad$ RPM of the propeller

- Engine current

- Engine voltage

Besides collecting the data with high precision, the complete measurement system is required to feature a lightweight design for use on the UAS. This ensures that the use of the testbed for further studies is not limited by the weight of the measurement unit.

\subsection{Sensor Unit}

The sensor unit is based on a standard tension/pressure sensor (HBM U9C 100N). For the sensor unit to be used on the unmanned test platform, the main focus is on a robust and compact lightweight design. The unit is designed to allow for the sensor to be installed without torque and bending moments introduced by the engine.

An engine connection unit is being developed for this purpose. This consists of an engine connection plate, a force introduction bolt and linear guide pins to absorb torsion and bending loads. These loads are directed from the linear guiding pins into the linear bearings installed in the load transmission frame. For the inflight thrust measurement, the sensor unit is installed directly between the engine mount and the engine (Figure 3).
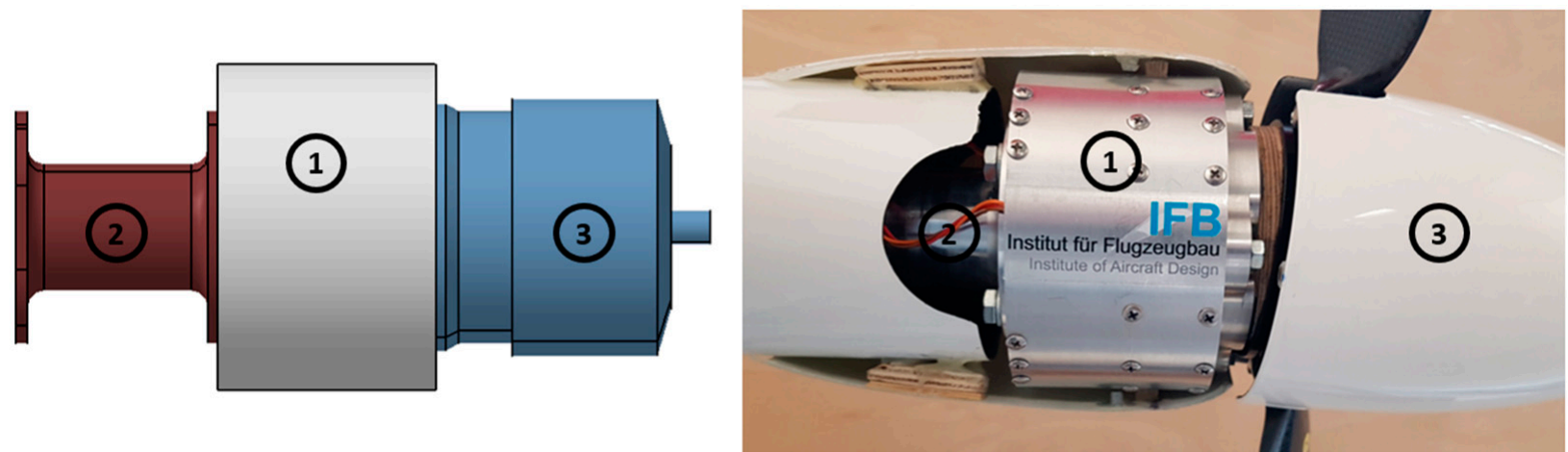

Figure 3. Integrated thrust measurement sensor unit; 1-Sensor Unit; 2-Engine Mount; 3-Electric Engine.

Due to its design, the sensor unit allows two separate load paths (Figure 4). Loads will be introduced in the sensor unit via the engine connection plate. The plate is linearly mounted and transmits the force induced by the propeller thrust as tension force directly to the sensor. The torque and the bending loads resulting from the angular and linear acceleration and vibrations of the engine are derived via the linear bearings into the structure of the sensor unit (housing and frames). This way the thrust can directly be derived from the measured tensile force. 


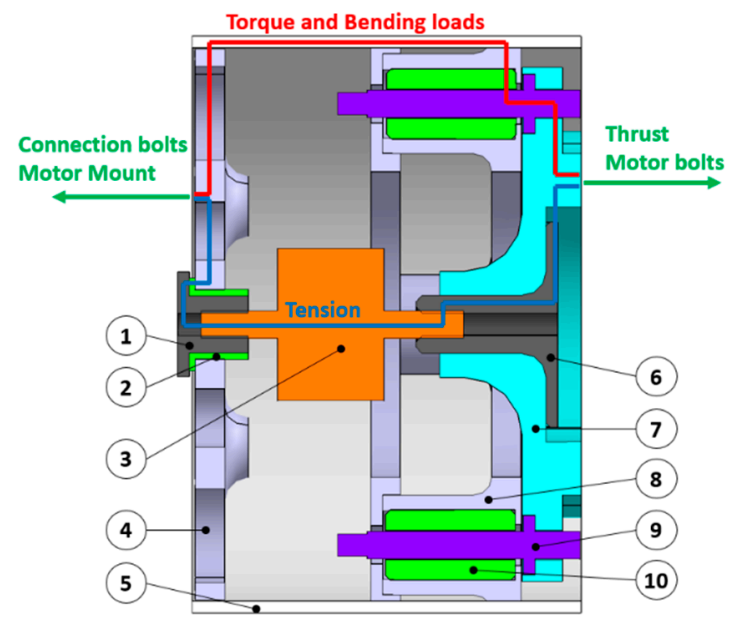

Figure 4. Sensor Unit (sectional view).

\subsection{Data Acquisition Unit}

The task of the data acquisition unit (Figure 5) is the acquisition and processing of data from the propulsion system and the transmission of the data to the board computer for synchronous logging. An STM32 microprocessor is used to convert analog signals, to encode and time stamp the data and to handle transmission to the central board computer via an RS485 bus (Figure 6). While this is sufficient to handle the sensor input from magnetic rpm measurements and current and voltage sensors, the force sensor outputs need to be amplified first. This is done using a miniaturized amplifier module (GSV-6CPU) installed on the Data Acquisition Unit. Additional interfaces on the data acquisition board allow to connect further sensors that might be required by future studies using the e-Genius-Mod test platform. With a weight of only $28 \mathrm{~g}$, the data acquisition unit (board without cable) is perfectly suited for use in UAS without restricting the payload capacity.

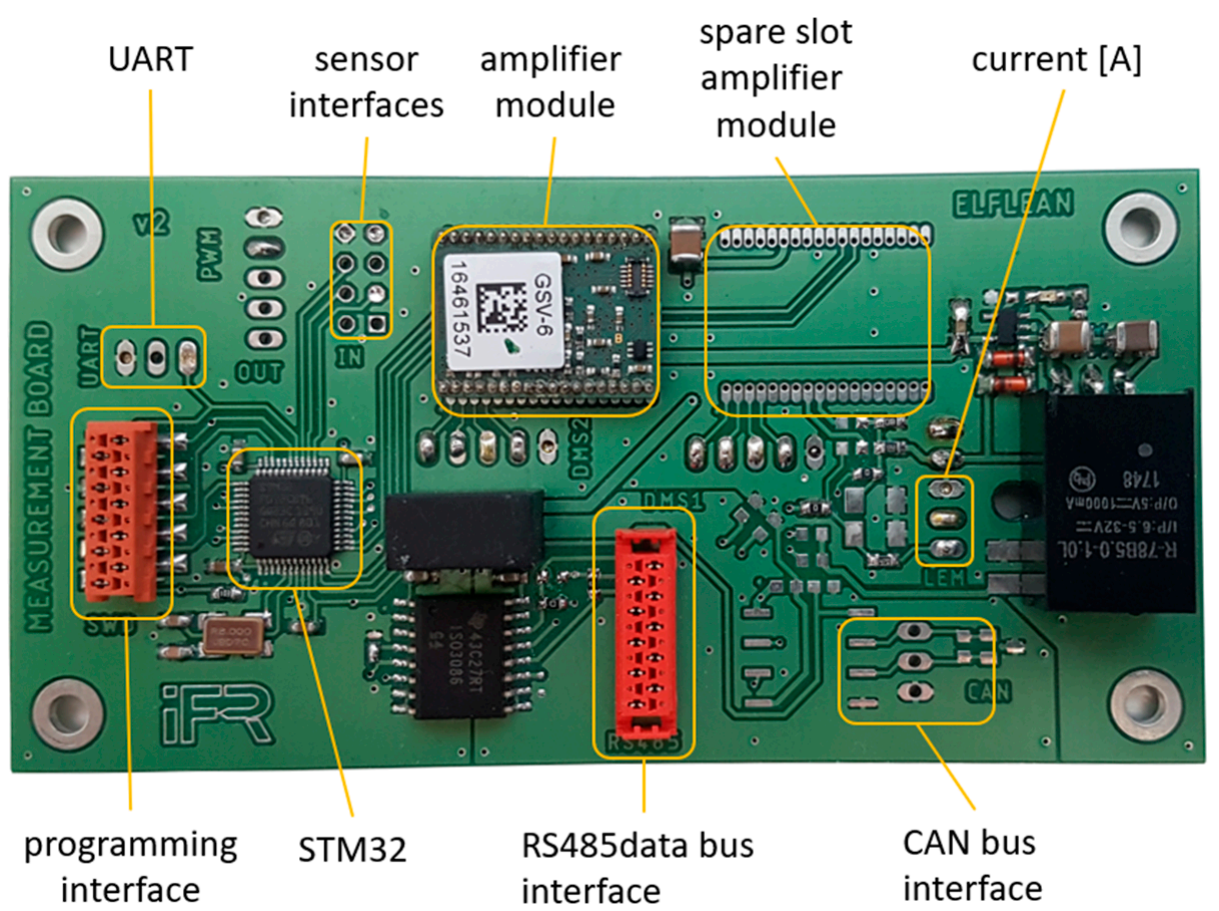

Figure 5. Data Acquisition Unit. tension rod (traction stop)

tension sensor

connecting frame

housing

orce introduction bolt

connection plate

linear guide pins

linear bearing 


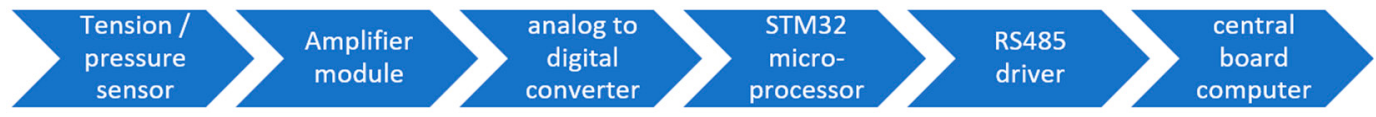

Figure 6. Information flow of the Data Acquisition Unit.

\section{Test Flight Analysis}

In order to obtain repeatable measurement flights, the flights are automatically guided along a previously planned flight path. The autopilot system [11] adjusts the flight condition to different, constant flight speeds at an altitude above mean sea level of $650 \mathrm{~m}$. This results in stable conditions in stationary horizontal flight, during which the corresponding input variables of the drive system are recorded. The available endurance of $85 \mathrm{~min}$ for one test flight allows for more than 68 measuring sections, which are segmented into phases with different flight velocities. With this, all measurements required for a characterization of the aerodynamic parameters of a configuration can be carried out in one single flight Figure 7 provides a synopsis of the legs and Table 3 presents the commanded velocities to identify the coefficients for lift and drag in flight.

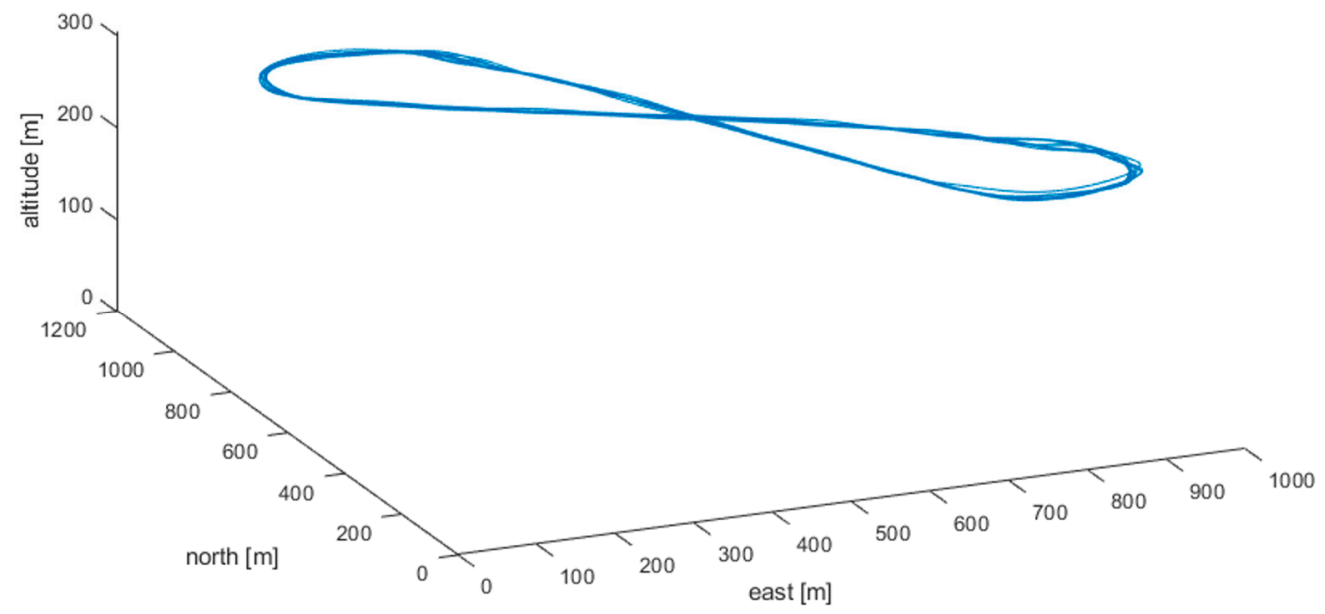

Figure 7. Section of the flight path from a single measurement flight.

Table 3. Mean standard deviation of velocity and altitude.

\begin{tabular}{cccc}
\hline \multicolumn{2}{c}{ Velocity $(\mathrm{m} / \mathbf{s})$} & \multicolumn{2}{c}{ Altitude $(\mathrm{m})$} \\
\hline Commanded & Standard Deviation & Commanded & Standard Deviation \\
\hline 20 & 0.23 & & 0.09 \\
21 & 0.23 & & 0.11 \\
22 & 0.21 & 300 & 0.12 \\
24 & 0.31 & & 0.12 \\
26 & 0.25 & 0.13 \\
28 & 0.22 & 0.11 \\
30 & 0.22 & 0.08 \\
32 & 0.20 & 0.08 \\
\hline
\end{tabular}

\section{Analysis of Static Horizontal Flight}

In order for the evaluation to be considered valid using the mean value method, the "section of measurement" must be carried out at a velocity and an altitude as constant as possible. The evaluation of the individual legs shows that both velocity and altitude are measured with only a very small standard deviation (Table 3 ) depending on the flight speed.

As expected, high fluctuations were detected in the recorded propeller speed, which is also reflected in the measured thrust values. This is a result of controlling the airspeed by using the thrust. The resulting control action can be seen in the resulting fluctuations 
in measured thrust values (Figure 8). They do not mainly represent a scattering in the aerodynamic drag, but moreover the necessary control action to keep the airspeed constant. This is particularly the case during the two turns.

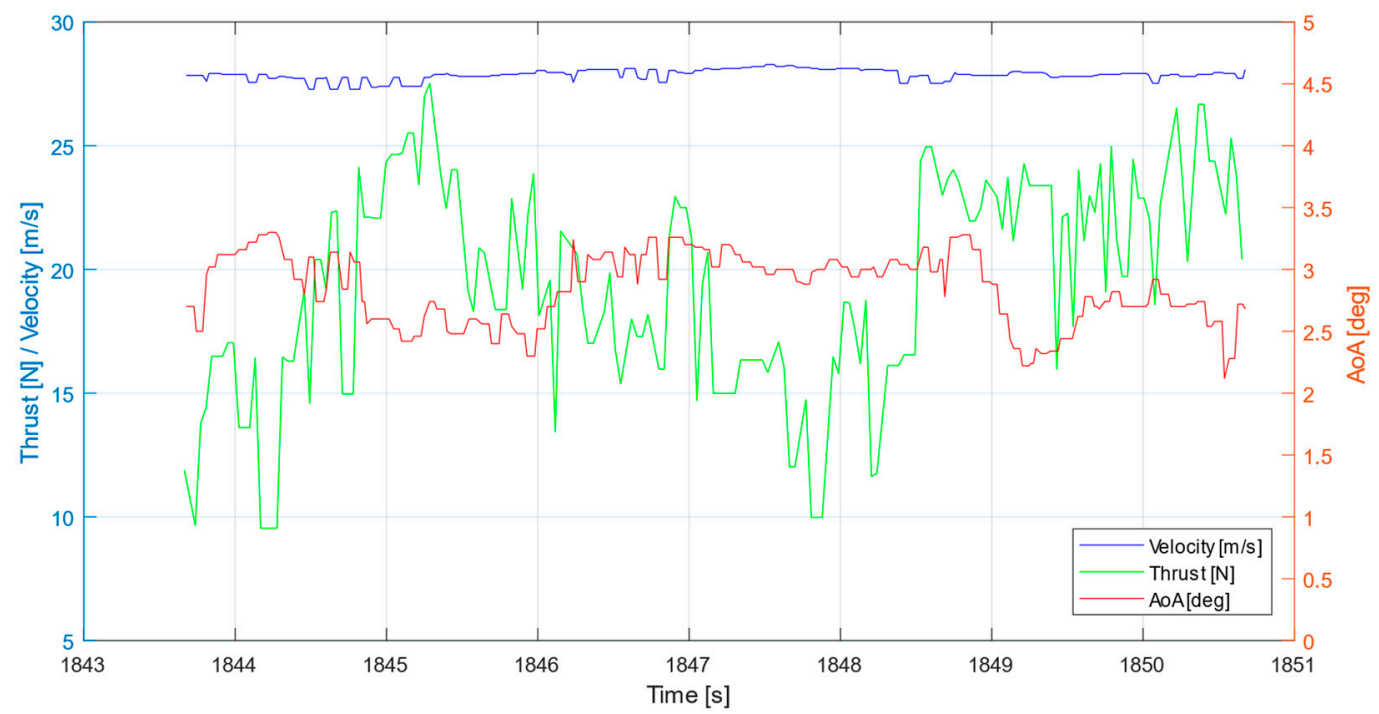

Figure 8. Example: Basic measurements on one single leg (with TAS $28 \mathrm{~m} / \mathrm{s}$ ).

The standard deviations caused by this must be taken into account accordingly in the evaluation and interpretation of the measured values. Nevertheless, the measured values on average give a good picture of the expected results and provide an excellent indication of the performance and aerodynamic quality of the aircraft.

For a first estimation and interpretation of the flight results, the values for thrust, angle of attack, lift and power are approximated as a function of 2nd order in dependence of the velocity as expected from the theoretical consideration. The assumption is based on the approximate relationship, that the lift increases linearly in relation to the AoA and the drag increases quadratic to the lift. Even if this procedure involves a degree of uncertainty in the interpretation of the results, it allows for an initial analysis of the aircraft characteristics, to provide input data for the aircraft design process.

\section{Results}

This section presents the results of the test flight presented in the previous section. Considering that the UAS should be used as a tool in aircraft design, the analysis focuses on the most interesting aspects for a design engineer. Figures 9 and 10 show the coefficients of lift and drag obtained from the measurement flights and the approximated resulting polar curve. As expected, due to the rpm variation described above, a significantly increased variation of the identified drag coefficient can be seen in Figure 10. Nevertheless, the values can be used for first design calculations. 


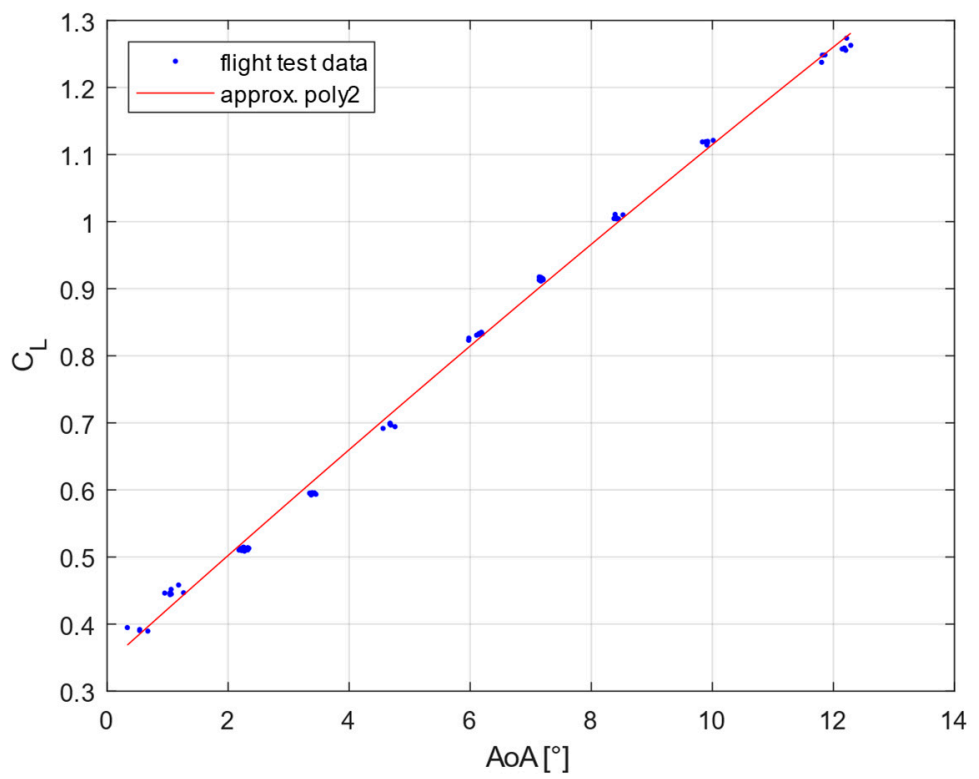

Figure 9. Lift polar.

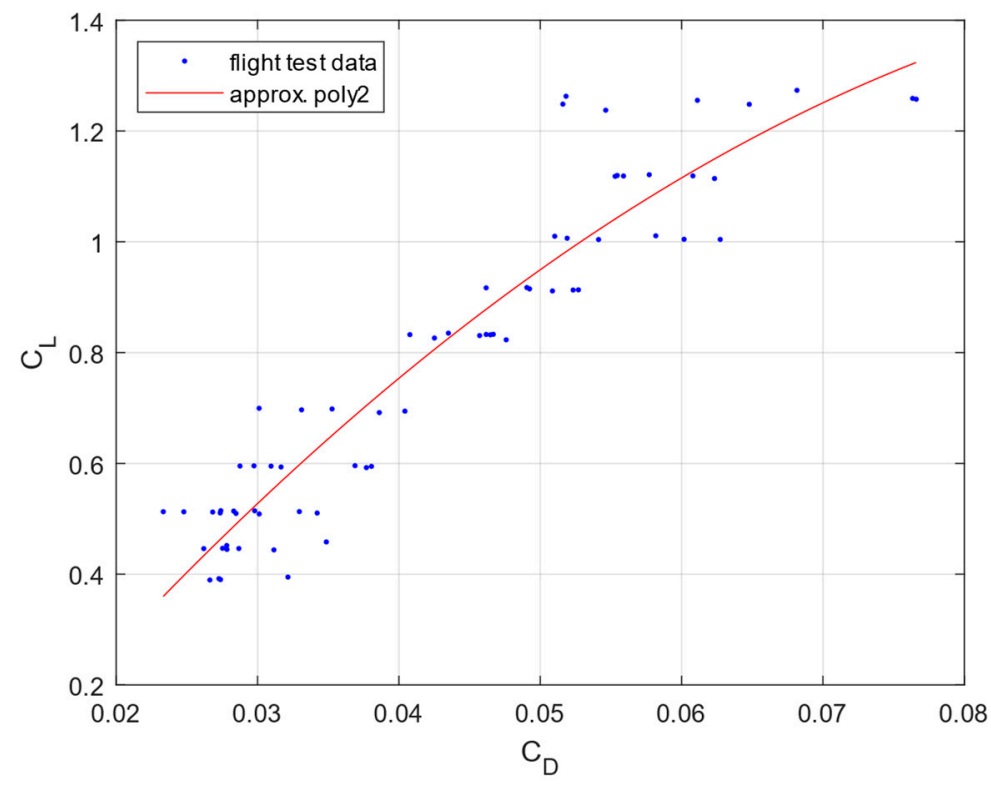

Figure 10. Drag polar.

Even if only a certain regime of the drag polar and the thrust to velocity curve is available, design points of interest (Table 4) can be estimated with the available identification. The points of maximum range and maximum endurance can directly be identified.

Table 4. Estimated points of max. range and max. endurance.

\begin{tabular}{ccc}
\hline & Max. Range & Max. Endurance \\
\hline Velocity & $20.96 \mathrm{~m} / \mathrm{s}$ & $20.15 \mathrm{~m} / \mathrm{s}$ \\
Glide Ratio & 17.96 & 17.88 \\
$C_{L}$ & 0.91 & 0.98 \\
$C_{D}$ & 0.0507 & 0.0548 \\
Thrust & $19.06 \mathrm{~N}$ & $19.04 \mathrm{~N}$ \\
\hline
\end{tabular}


The point of maximum range is given by the maximum of the glide ratio $\left(C_{L} / C_{D}\right)$ and can be determined directly from Figures 10 and 11 . The point of maximum endurance can be determined as point of minimum required thrust (min drag) in Figure 12.

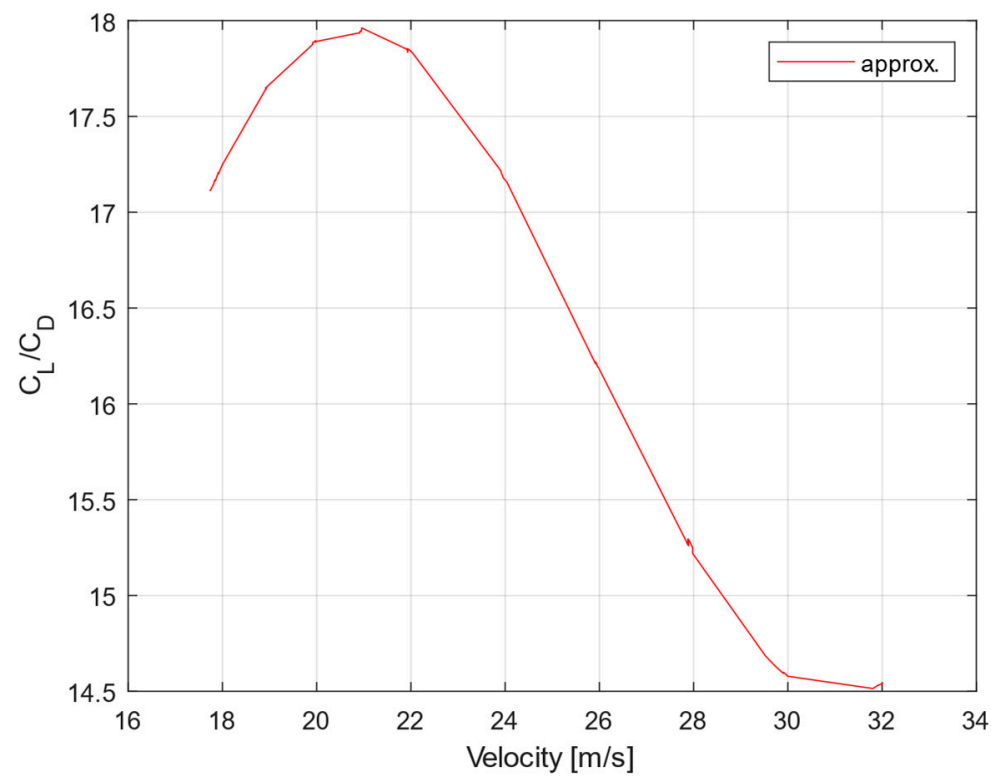

Figure 11. Glide ratio $\left(C_{L} / C_{D}\right)$ to velocity.

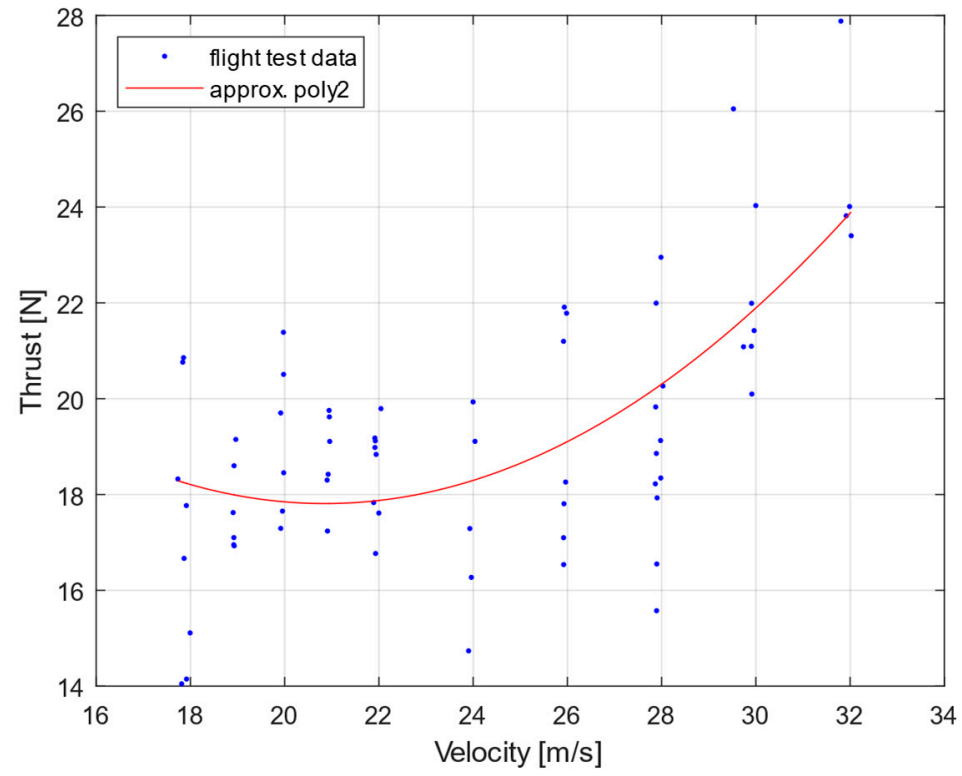

Figure 12. Thrust to velocity.

With the knowledge of the electrical power and the power output of the propeller in terms of thrust, the overall efficiency of the test platform can be determined (Figure 13). 


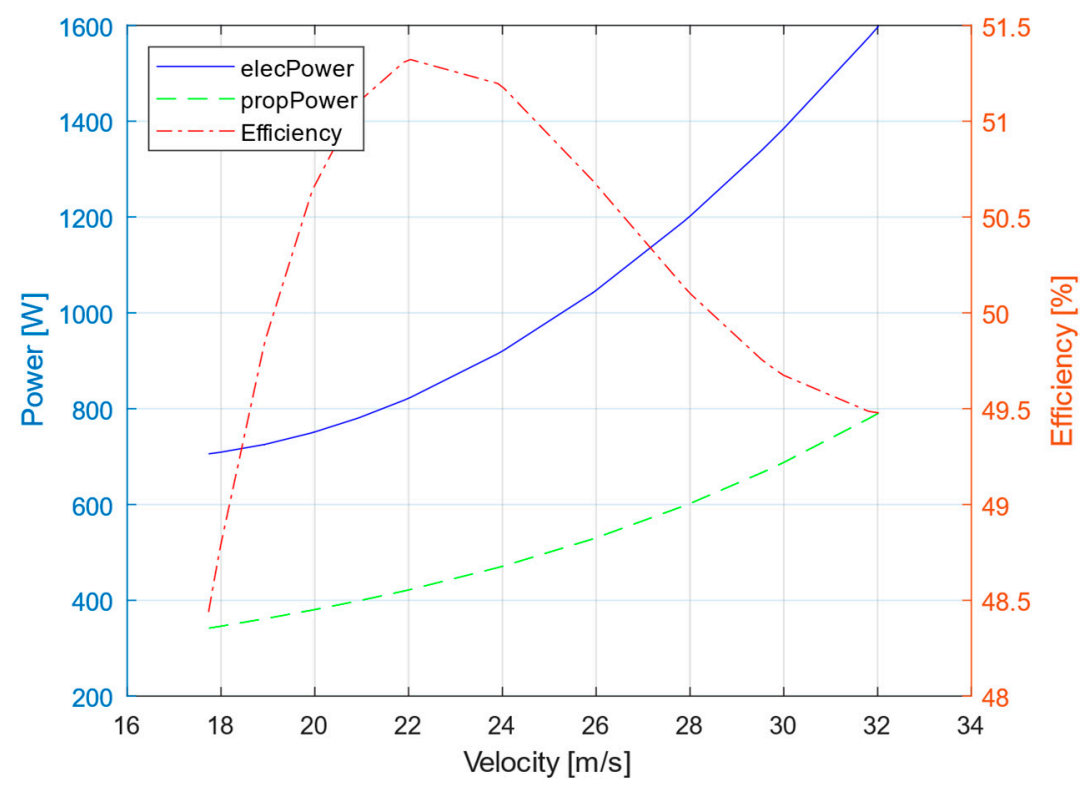

Figure 13. Performance and Efficiency of the free-flight test platform for different velocities.

\section{Discussion}

The measurements obtained from the flight tests provided the expected results with regard to the thrust curves and the resulting polar. As a first comparison between flight test results and a simulation of the wing airfoil, the gradient of lift coefficient versus the angle of attack was assessed. A comparison with the lift of the airfoil simulated in XFoil [13] shows a very good agreement with reality (Figure 14). The slight deviation of the slope of the two curves results from the influence of the lift distribution on the real wing caused by the boundary vortices.

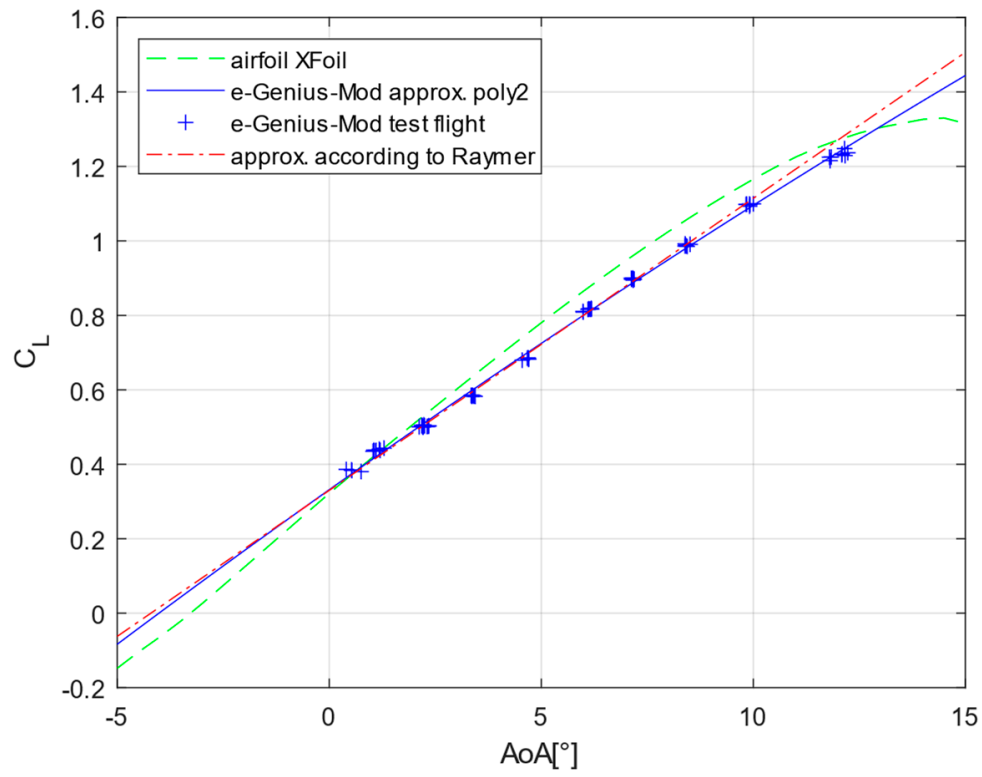

Figure 14. Comparison of XFoil airfoil simulation, semi empirical method and flight test data.

The amount of the deviation depends on the aspect ratio $(A R)$ of the wing and can be calculated approximately [14] as follows with $b$ describing the wing span and $S$ the reference wing area:

$$
\frac{d C_{L}}{d A o A}=\frac{A R}{(2+A R)} * 2 \pi \text { with } A R=\frac{b^{2}}{S}
$$


The angle of attack for zero lift is found as $-3.8^{\circ}$ from interpolation of the measured values from real flight, which gives a good agreement with the value expected from the simulation. The corresponding installation position of the air data probe in relation to the wing's angle of attack is thus correctly recorded.

An additional validation method was performed, calculating the wing's lift curve slope with a semi-empirical formula [15], applicable for subsonic design.

$$
C_{L_{A o A}}=\frac{2 \pi A R}{2+\sqrt{4+\frac{A R^{2} \beta^{2}}{\eta^{2}}\left(1+\frac{\left(\tan A R_{\text {max }_{t}}\right)^{2}}{\beta^{2}}\right)}}\left(\frac{S_{\exp }}{S}\right) F
$$

Within formula (6) $\eta$ describes the so-called efficiency of the airfoil and is approximately 0.95 according to [15]. $\beta^{2}$ considers the flight velocity respectively the Mach number (M).

$$
\beta^{2}=1-M^{2}
$$

The wing geometry and the influence of the wing are considered in Equation (7) with $A R_{\text {max }_{t}}, S_{\text {exp }}$ and $F: A R_{\text {max }_{t}}$ is the aspect ratio of the wing section with the thickest airfoil chord location. The wing area exposed by the fuselage is considered with $S_{\text {exp }}$ and the lift generated by the wing is approximated with $F$ estimated via the diameter $d$ of the fuselage tube under the wing. According to Raymer [15], these can be calculated as follows.

$$
F=1.07\left(1+\frac{d}{b}\right)^{2}
$$

To consider also the effects of the winglet the effective aspect ratio of the wing is estimated according to [14] taking into account the height of the winglets $h$ in relation to the wing span.

$$
A R_{e f f}=A R\left(1+1.9 \frac{h}{b}\right)
$$

The polar of the calculated lift curve slope $\left(C_{L_{A o A}}=0.0764\right)$ is plotted in Figure 14 and the zero crossing is shifted by the estimated $=0.33$. In a direct comparison of the part of the lift polar which can be considered as nearly linear between the semi-empirical and the measured lift curve slope with $C_{L_{A o A \text { measured }}}=0.0787$ for $\left(0^{\circ}<A O A<5^{\circ}\right)$ a good match is achieved with only $3.01 \%$ deviation of the curve slope.

In the simplified approach used in this paper, the possible error in the results must also be considered. A relatively small error can be assumed for the lift coefficient. This error is made up of the accuracy of the air data probe (measurement error flow angle: $<1.0^{\circ}$, velocities: $<1.0 \mathrm{~m} / \mathrm{s}$ ) and a possible installation error which is corrected in the post processing. The drag measurement must be viewed with greater caution. The accuracy of the measuring system has been demonstrated under laboratory conditions, the variation of the measured thrust values due to the fluctuating speed controller (see Section 5) leads to a high standard deviation (mean $26.56 \%$ ).

Nevertheless, the thrust measuring system generated usable data, which, however, are subject to fluctuations due to controlling thrust values. This must be considered in the evaluation. For further flight tests, control authority for the airspeed control should be reduced in order to ensure that the measured thrust values are smoother and there is less scattering. The proper functioning of the measuring system was verified in laboratory tests before and after the flight tests.

The measurement of the thrust finally gives information about the total drag, which is necessary to establish the drag polar and aerodynamic parameters of interest. From the illustrations in the "results" section the corresponding statements regarding the aerodynamic performance of the system can be derived. The values are within the predicted range. As expected, the scaling of the aircraft brings the optima for best range and flight duration very close together. By measuring the thrust during flight while simultaneously 
observing the electrical power consumption, a direct statement can also be made about the overall efficiency of the drive train. It can be seen from Figure 13 that the optimum efficiency is found in the range of the speed at which the system is operated in the glide ratio of best range. This is an important step to assess the impact of future design changes to the e-Genius Mod.

\section{Conclusions}

The measurement flights with the unmanned e-Genius-Mod test platform have shown that on-board thrust measurement provide a direct method to characterize the aircraft. The expectations to draw direct conclusions about the aerodynamic performance could be met. With the presented novel measurement system for direct, in-flight thrust measurements, the unmanned platform represents a useful tool in aircraft design as a "flying wind tunnel". It allows an identification of the flight performance and allows to evaluate the effects of new technologies and configurations. This is of particular interest for new configurations that use distributed electric propulsion to increase efficiency and to enable a future cleaner and greener aviation.

To improve the quality of the flight test results in the future and to allow for drag estimation from non-steady flight conditions, the aircraft dynamics will be included in the drag estimation through acceleration measurements from an inertial measurement unit. Using the thrust measurement system, the characterization of the aircraft could be completed to such an extent that further flight tests with modified settings and distributed propulsion systems can follow. Due to the performance measurements on the baseline configuration it will be possible in the future to draw direct comparisons to flight tests with modified configurations. The measurement system used has been verified and can now also be used for further configurations utilizing distributed propulsion. For this, the sensor unit will be miniaturized to be able to measure the thrust of each propulsion unit in flight. The additional measuring technology installed to record the aerodynamically relevant input variables perfectly complements the thrust measurement of the main propulsor. Therefore, the basic configuration of the e-Genius-Mod is now available for more extensive flight tests and offers ideal conditions for scaled flight tests of all kinds.

Author Contributions: Conceptualization, D.P.B.; methodology, D.P.B., J.D., and O.P.; investigation, D.P.B., J.D., and O.P.; writing-original draft preparation, D.P.B., and J.D.; writing-review and editing, D.P.B., J.D., O.P., S.N., and A.S.; supervision, W.F., and A.S.; project administration, D.P.B.; funding acquisition, D.P.B., S.N., W.F., and A.S. All authors have read and agreed to the published version of the manuscript.

Funding: This research was supported by Federal Ministry for Economic Affairs and Energy on the basis of a decision by the German Bundestag. Project: ELFLEAN_Electric wing tip propulsion system for the development of energy-efficient and noise reduced airplanes (20E1706).

Institutional Review Board Statement: Not applicable.

Informed Consent Statement: Not applicable.

Data Availability Statement: Data not yet available public.

Conflicts of Interest: The authors declare no conflict of interest.

\section{References}

1. Wilson, T.; Kirk, J.; Hobday, J.; Castrichini, A. Small scale flying demonstration of semi aeroelastic hinged wing tips. In Proceedings of the International Forum on Aeroelasticity and Structural Dynamics 2019, Savannah, GA, USA, 9-13 June 2019.

2. Süelözgen, Ö.; Wüstenhagen, M. Operational modal analysis for simulated flight flutter test of an unconventional aircraft. In Proceedings of the International Forum on Aeroelasticity and Structural Dynamics 2019, Savannah, GA, USA, 9-13 June 2019.

3. Kuehme, D.; Alley, N.R.; Phillips, C.; Cogan, C. Flight Test Evaluation and System Identification of the Area-I PrototypeTechnology-Evaluation Research Aircraft (PTERA). In Proceedings of the AIAA Flight Testing Conference, Atlanta, GA, USA, 16-20 June 2014. [CrossRef] 
4. Cogan, B.; Alley, N.; Hange, C.; Nguyen, N.; Spivey, D. Flight Validation of Cruise Efficient, Low Noise, Extreme Short Takeoff and Landing (CESTOL) and Circulation Control (CC) for Drag Reduction Enabling Technologies; Presentation, NASA Aeronautics Research Mission Directorate, Seedling Technical Seminar; NASA Aeronautics Research Mission Directorate: Washington, DC, USA, 2014.

5. Ortiz, P.; Alley, N. Spanwise Adaptive Wing—PTERA Flight Test; AIAA Aviation Forum: Atlanta, GA, USA, 2018; NASA Document ID 20180004640.

6. Bergmann, D.P.; Denzel, J.; Baden, A.; Kugler, L.; Strohmayer, A. Innovative Scaled Test Platform e-Genius-Mod-Scaling Methods and Systems Design. Aerospace 2019, 6, 20. [CrossRef]

7. Geiß, S.; Notter, S.; Strohmayer, A.; Fichter, W. Optimized Operation Strategies for Serial Hybrid-Electric Aircraft. In Proceedings of the AIAA Conference: Aviation Technology, Integration, and Operations Conference, Atlanta, GA, USA, 25-29 June 2018. [CrossRef]

8. Edwards, D. Performance Testing of RNR's SBXC Using a Piccolo Autopilot, Technical Report. 2008. Available online: http:/ / soaring. goosetechnologies.com (accessed on 1 November 2020).

9. Norris, J.; Bauer, A.B. Zero-Thrust Glide Testing for Drag and Propulsive Efficiency of Propeller Aircraft. J. Aircr. 1993, 30, 505-511. [CrossRef]

10. Bronz, M.; Hattenberger, G. Aerodynamic Characterization of an Off-the-shelf Aircraft via Flight Test and Numerical Simulation. In Proceedings of the AIAA Flight Testing Conference, Washington, DC, USA, 13-17 June 2016. [CrossRef]

11. Stephan, J.; Pfeifle, O.; Notter, S.; Pinchetti, F.; Fichter, W. Precise Tracking of Extended Three-Dimensional Dubins Paths for Fixed-Wing Aircraft. J. Guid. Control. Dyn. 2020, 43, 2399-2405. [CrossRef]

12. Pfeifle, O.; Fichter, W.; Bergmann, D.; Denzel, J.; Strohmayer, A.; Schollenberger, M.; Lutz, T. Precision performance measurements of fixed-wing aircraft with wing tip propellers. In Proceedings of the AIAA Aviation 2019 Forum, Dallas, TX, USA, 17-21 June 2019. [CrossRef]

13. Baden, A. Entwurf eines Freiflugmodells des E-Motorseglers e-Genius unter Berücksichtigung der Aerodynamischen Vergleichbarkeit. Bachelor's Thesis, University of Stuttgart, Institute of Aircraft Design, Stuttgart, Germany, 2016.

14. Schlichting, H.; Truckenbrodt, E. Aerodynamik des Flugzeuges; Springer: Berlin/Heidelberg, Germany, 2001; Volume 2. [CrossRef]

15. Raymer, D.P. Aircraft Design: A Conceptual Approach, 2nd ed.; AIAA: Washington, DC, USA, 1989; ISBN 0-930403-51-7. 